\title{
A QUESTÃO DA INTENCIONALIDADE NO ASSÉDIO MORAL
}

The issue of intentionality in moral harassment

La question de l'intention dans l'intimidation

La cuestión de la intencionalidad en el acoso moral

Lis Andrea Soboll ${ }^{1}$

Psicóloga pela UFPR. Doutora em Medicina Preventiva pela USP. Professora no Departamento de Psicologia. Coordenadora do grupo de pesquisa Trabalho e Processo Subjetivação - UFPR.

Thaís Miara ${ }^{2}$ Psicóloga. Membro do grupo de pesquisa Trabalho e Processo Subjetivação - UFPR.

Juliana Moscalewsky $\mathbf{y}^{3}$ Graduanda em Psicologia - UFPR. Membro do grupo de pesquisa Trabalho e Processo de Subjetivação - UFPR.

\section{RESUMO}

O presente artigo aborda uma discussão teórica sobre a questão da intencionalidade na caracterização dos casos de assédio moral, apresentando dois posicionamentos distintos. O primeiro deles toma a intencionalidade como critério obrigatório para caracterização do assédio, enquanto o segundo a trata como elemento complementar para a caracterização do assédio. Contempla também as implicações do uso da intencionalidade como critério obrigatório, passando pela questão das responsabilidades, tomando como dados de realidade três ações julgadas no judiciário trabalhista. Conclui-se que a intencionalidade no assédio moral é abordada com frequência na literatura, com superficialidade e pouca clareza, dando espaço para que este critério, quando adotado como obrigatório, leve a uma análise que tende a buscar culpados, com repercussões na área da saúde, da gestão e do direito.

Palavras-chave: assédio moral; violência no trabalho; responsabilidade

\section{ABSTRACT}

The present article addresses a theoretical discussion about the question of intentionality in the characterization of cases of moral harassment, presenting two distinct positions. The first one takes intentionality as a mandatory criterion for characterizing harassment, while the second treats it as a complementary element to the characterization of harassment. The article also contemplates the implications of the use of intentionality as a mandatory criterion in the characterization, going through the is ue of responsibilities and taking as reality data three lawsuits adjudicated in the labor court. It is concluded that intentionality in moral harassment is often addressed in the literature with superficiality and lack of clarity, what makes the adoption of it as a criterion lead

\footnotetext{
${ }^{1}$ lisdrea@gmail.com

2 thamiara@gmail.com

3 juliana.moscalewsky@gmail.com
} 
to an analysis that tends to seek someone as the guilty, and reverberates in the health area, as well as in management and law.

Key words: bullying; workplace violence; responsibility.

\section{RÉSUMÉ}

Cet article traite d'une discussion théorique sur la question de l'intentionnalité dans la caractérisation des cas de harcèlement moral, en présentant deux positions distinctes. Le premier prend l'intentionnalité comme un critère obligatoire pour caractériser le harcèlement, tandis que le second le considère comme un élément complémentaire de la caractérisation du harcèlement. Cet article comprend également les implications de l'utilisation de l'intentionnalité comme critère obligatoire, en passant par la question de la responsabilité et en prenant trois actions décidées dans la cour du travail comme données de réalité. Nous concluons que l'intention dans le harcèlement est souvent abordée dans la littérature avec superficialité et le manque de clarté, ce qui donne un espace à que ce critère, lorsqu'il est adopté comme obligatoire, conduire à une analyse qui tend à déclarer un coupable, avec des répercussions sur la santé, la gestion et le droit.

Mots-clés: harcèlement moral ; violence au travail; responsabilité.

\section{RESUMEN}

El presente artículo aborda la cuestión de la intencionalidad en la caracterización de los casos de acoso moral, presentando dos posicionamientos distintos: 1. Intencionalidad como criterio obligatorio para caracterización del acoso y 2. Intencionalidad como elemento complementario para la caracterización del acoso. También contempla las implicaciones del uso de la intencionalidad como criterio obligatorio, pasando por la cuestión de las responsabilidades, tomando como datos de realidad tres acciones juzg adas en el poder judicial. Se concluye que la intencionalidad en el acoso moral se aborda con frecuencia en la literatura, con superficialidad y poca claridad, dando espacio para que este criterio, cuando se adopta como obligatorio, lleve a un análisis que tienda a buscar culpables, con repercusiones en el área de la salud de la gestión y del derecho.

Palabras clave: acoso moral; violencia en el trabajo; responsabilidade.

\section{INTRODUÇÃO}

A violência no trabalho não é um fenômeno novo e provavelmente vem sendo praticada desde o início das relações de trabalho. Heinz Leymann foi $o$ primeiro pesquisador a se debruçar sobre o tema e identificou comportamentos hostis contra trabalhadores em seus locais de trabalho, tendo denominado esta prática de mobbing. O termo assédio moral foi cunhado pela psiquiatra Marie-France Hirigoyen e chegou ao Brasil com a tradução da obra "Assédio moral: a violência perversa no cotidiano" (2000), e om a publicação da tese de mestrado de Margarida Barreto, em 2003, intitulada Violência, saúde, trabalho: uma jornada de humilhações.

Ao longo dos anos, inúmeras terminologias foram utilizadas para se referir ao tema- por exemplo, harassment, mobbing, bullying, acoso ou maltrato psicológico, molestie psicologiche- bem como diferentes critérios de identificação foram propostos (Soboll, 2008). Sendo assim, mesmo que o assédio venha sendo discutido no Brasil desde a década de 2000, até hoje predomina uma complexidade para identificação de casos na realidade tendo em vista a diversidade de conceitos adotados e suas variações em relação aos critérios definidores.

O presente estudo aborda especificamente a questão da intencionalidade na caracterização dos casos de assédio moral, apresentando dois posicionamentos distintos: a intencionalidade como critério obrigatório para caracterização do assédio e a intencionalidade como elemento complementar para a caracterização do assédio. Elaborado na forma de um ensaio teórico, este texto contempla também a discussão sobre as implicações do uso da intencionalidade como critério 
obrigatório, passando pela questão da responsabilidade, tomando como referência de realidade algumas ações julgadas no judiciário trabalhista.

\section{Caracterização do assédio}

Existem diversas terminologias que se referem ao assédio moral, mas, apesar disso, elas parecem nomear uma mesma prática, a saber: "um conjunto de atos hostis, que ocorre de forma crônica, continuada e repetitiva, os quais atingem a dignidade, ofendem ou prejudicam aqueles que são alvos das hostilizações" (Soboll, 2017). Comparando os conceitos de assédio moral definidos por Soboll (2011, 2013, 2017), Heloani e Barreto (2008, 2010), Einarsen (2001), Chappell e Di Martino (2006), e formas variadas, mais ou menos sutis Vieira, Lima e Lima (2012) é possível encontrar elementos comuns importantes para a conceituação e caracterização do assédio moral, que serão norteadores para a abordagem do tema no presente trabalho. Destacam-se como aspectos relevantes para o assédio moral, nestes diferentes autores: definição do assédio moral como uma forma de violência psicológica que compreende atos negativos- como hostilização, opressão, humilhação, intimidação e ofensas- sendo praticados de forma frequente, duradoura e que se prologam no tempo. Esses comportamentos podem se manifestar de, implicando na exposição frequente dos trabalhadores a situações vexatórias e constrangedoras, acarretando sentimentos de menos-valia, insatisfação, desanimo, indignação e podendo chegar a afetar, com o passar do tempo, a autoestima e saúde mental do trabalhador.

Conforme trabalhos de Einarsen, Hoel, Zapf e Cooper (2003) e Gosdal e Soboll (2009), o assédio moral, conforme as características descritas acima, pode se apresentar de duas formas distintas; ele pode se referir às relações interpessoais hostis (assédio moral interpessoal), bem como à violência advinda da própria organização por meio de seus processos e políticas, denominado de assédio moral organizacional. Importa aqui a discussão da intencionalidade nas práticas de assédio moral, independentemente das suas formas de expressão.

\section{Intencionalidade no assédio moral}

A intencionalidade no assédio moral é um tema controverso e os autores que tratam dela podem ser divididos em dois grupos de acordo com suas perspectivas. No primeiro grupo se encontram autores que defendem a existência e importância da identificação da intencionalidade para 0 reconhecimento do assédio moral no trabalho, sendo ela critério obrigatório para a sua caracterização. Para esses autores o assédio moral é um processo violento premeditado, ou seja, que "contém intenção" (Barreto, 2013, p.19). Ela é entendida como "própria da atividade humana", diferentemente do que ocorre com os animais, os quais agem instintivamente (Heloani \& Barreto, 2010; Barreto, 2013). Barreto (2013) esclarece: "quem pratica [o assédio] normalmente sabe o que está fazendo, a quem está abordando e porque o está atingindo. Deste modo, os atos de violência não estão no âmbito do instinto, da coisa impensada, da agressividade simples e pura daquele que assedia" (Barreto, 2013, p.19).

Hirigoyen (2009, 2011), Freitas, Heloani e Barreto (2008), Heloani e Barreto (2010) entendem que o agressor age sempre com o objetivo de prejudicar, danificar, humilhar, isolar e demolir psiquicamente a vítima (Hirigoyen, 2011; Freitas, 2007; Freitas, Heloani, \& Barreto, 2008). Segundo Hirigoyen (2011), o trabalho é apenas o meio encontrado para a destruição do outro, pois o que o agressor visa é atingir a personalidade da vítima. Para a autora, é justamente esse tipo de intenção por parte do agressor que possibilita a caracterização da violência como assédio moral, diferenciando-a das demais formas de violência no trabalho. Nesta perspectiva, o assédio moral só 
existe quando há algum tipo de intenção maldosa, de causar prejuízo, por parte do autor das agressões (Hirigoyen, 2011). Considera-se assim que a intenção do agressor é origem da violência, ou seja, a raiz do assédio é a intenção maldosa do agressor. Para Gaulejac (2007) e Vieira et al. (2012) esta abordagem acaba por relegar os demais fatores que determinam o assédio moral, como as pressões que sofrem os trabalhadores para alcançarem as metas, sobrecarga de trabalho e as formas de organização da produção e do trabalho.

No segundo grupo, com o qual concordamos, encontram-se autores que tratam sobre a intencionalidade como critério complementar para a caracterização do assédio. De acordo com Einarsen, Hoel, Zapf e Cooper (2010) "para considerar a intencionalidade como parte da definição de assédio seria necessário clarificar a que a "intenção" se refere, pois muitas são as possibilidades" (p. 19). A partir destes argumentos os autores propõem a exclusão da intencionalidade da definição de assédio por não ser passível de comprovação.

Schatzmam, Gosdal, Soboll e Eberl (2009) entendem que o assédio moral é intencional, mas reconhecem a dificuldade de mensuração desse elemento. Por ser impossível avaliar a intencionalidade, essa só deve ser considerada em contextos específicos, como na clínica psicológica, que parte da percepção ou relato do paciente, e no âmbito jurídico, em que essa questão é relevante para fixação da penalidade ou multa (Schatzmam et al., 2009).

Nesta mesma linha, Soboll (2017) entende a intencionalidade como um elemento extremamente complexo e frágil para ser colocado como critério obrigatório de identificação do assédio moral, uma vez que sua avaliação é demasiado subjetiva.

Além dessa diferença de opiniões sobre a obrigatoriedade da intencionalidade na caracterização do assédio moral, os autores parecem não entrar em consenso sobre o objetivo dessa intencionalidade e se ela é consciente ou inconsciente. Os autores Hirigoyen (2011), Freitas (2007), Freitas, Heloani e Barreto (2008) propõem que o assédio moral tem objetivos múltiplos, ainda que não contraditórios, pois visa humilhar, prejudicar e destruir psiquicamente a vítima. Todavia, humilhar, prejudicar e destruir são objetivos muito diferentes e distantes entre si no que se refere à intensidade das agressões e suas consequências.

A humilhação é considerada pela maioria dos autores (Einarsen et al., 2003; Freitas, 2007; Freitas, Heloani, \& Barreto, 2008; Hirigoyen, 2009; Heloani \& Barreto, 2010; Hirigoyen, 2011) como objetivo das agressões, todavia adota-se o entendimento de Soboll (2011) e Horst e Soboll (2013) de que essa é uma consequência e não um objetivo. Isto porque além de ser impossível averiguar a existência de um intuito ou objetivo ou mensurá-lo, as humilhações podem ocorrer sem que exista o intuito de cometê-las, em consequência da perseguição de outro objetivo, por exemplo (Einarsen et al., 2010; Soboll, 2011).

Além disso, como especificar o objetivo da intencionalidade se nem sequer há clareza de sua definição e delimitação? Muitos dos estudos sobre o assédio demonstram limitações em sua capacidade de captar toda a complexidade que envolve o assédio moral, pois foram realizados com base apenas nos relatos das vítimas, o que possibilita tratar apenas da intencionalidade na forma como ela é percebida por aqueles que foram alvos das hostilizações. Entende-se que a análise daqueles que são apontados como agressores é essencial para a questão da intencionalidade.

Sobre o nível de consciência presente nos casos de assédio moral, Einarsen et al. (2003), Soboll (2011) e Horst e Soboll (2013) propõem que a intenção pode ser tanto consciente quanto inconsciente. Mattiesen e Einarsen (2001) acrescentam que pode também ser 
parcialmente consciente. A partir do levantamento bibliográfico foi possível perceber que a maioria dos estudiosos que defendem a importância da intencionalidade na caracterização do assédio consideram-na como consciente (Freitas, Heloani, \& Barreto, 2008; Heloani \& Barreto, 2010) e os que prescindem dessa entendem que pode ser consciente e inconsciente (Einarsen et al., 2003, 2010; Horst \& Soboll, 2013; Schatzmam et al., 2009; Soboll, 2011;).

Independentemente do nível de consciência, abordar a intencionalidade é possível apenas a partir do relato do agressor, o que dificulta a sua averiguação e comprovação (Einarsen et al., 2003, 2010; Soboll, 2011). Por esse motivo, a maioria dos estudiosos europeus a desconsideram (Einarsen et al. 2003, 2010). Além disso, possibilitar que a opinião do próprio agressor tenha relevância na caracterização de uma situação de violência que ele mesmo propiciou é altamente questionável (Einarsen et al., 2003).

Mas afinal, quais as implicações em se considerar a sua existência a nível consciente ou inconsciente? Tanto na Psicologia quanto no Direito a consciência está associada a um saber, ciência e a responsabilidade. No campo do Direito, a responsabilidade jurídica está estreitamente associada com o saber de duas formas distintas: ela impõe-se ao sujeito quando ele sabia o que fazia e também quando não sabia o que deveria fazer, pois não teve acesso a um conteúdo que, a princípio, seria universal (Forbes, 2012).

A responsabilidade está relacionada ao conhecimento e a moral, conforme apontam os conceitos jurídicos de dolo e culpa. Em nosso país se responde criminalmente, por exemplo, quando há a intenção de cometer o crime ou de se obter um resultado criminoso (dolo), ou então, como na minoria dos casos, quando há imperícias, negligencia ou imprudência (culpa). Portanto, no Direito, responde-se por saber qual o resultado desejado das ações e os meios de consegui-lo (crime doloso) ou por aquilo que se sabia ou deveria saber (risco previsto) (Forbes, 2012). Assim, entendemos que a perspectiva do Direito se refere a uma responsabilidade estreitamente relacionada com a consciência pela das ações.

Assumindo que a consciência está relacionada à responsabilização então é possível pensar, à primeira vista, que o inconsciente ou atos inconscientes implicam em uma falta de responsabilização do indivíduo por suas atitudes e pelas consequências dessas. De acordo com o psicanalista Forbes (2012), durante muito tempo, mesmo no meio psicanalítico, aquela concepção esteve bastante presente, podendo ser representada pela máxima "só se foi meu inconsciente", com uma forma de desresponsabilizar-se de algo. Logo, onde "há inconsciente não poderia haver responsabilidade" (Forbes, 2012). Todavia essa ideia é resultado de uma incompreensão da psicanálise, a qual busca justamente o contrário: que o sujeito se implique e responsabilize-se por todas as suas ações, mesmo aquelas motivadas por mecanismos que lhe são obscuros (inconscientes). Nesse sentido, Forbes (2012) propõe que a concepção psicanalítica de responsabilização supera $o$ direito, porém sem excluí-lo.

Forbes (2012) explica que o Direito se restringe aos conteúdos que são acessíveis ao ego (conscientes), os quais correspondem a uma pequena parcela do aparelho psíquico humano. E a psicanálise tem como foco justamente os conteúdos que são inacessíveis ao ego, àqueles que são inconscientes. Segundo ele, "o inconsciente que move o homem o faz sempre dolosamente. E disso, o ego nada consegue prever. Em que preocupe o jurista que gosta de moral penal, a ação humana guarda sempre o imprevisível ao ego (...)" (Forbes, 2012, p. 149). Portanto, a psicanálise questiona, coloca em cheque a forma como o Direito olha essa questão. 
Todavia isso não desimplica o sujeito da psicanálise, conforme afirma Lacan no axioma: "por nossa condição de sujeito somos sempre responsáveis" (Lacan, 1996, 1998, p. 873 apud Forbes, 2012). Em relação ao axioma, Forbes (2012) destaca: “'sempre', não de vez em quando ou dependendo da intenção, do conhecimento ou qualquer outra variável. Se o sujeito é sempre responsável não há sujeito sem responsabilidade" (p.121).

A psicanálise visa então que o sujeito se responsabilize pelo que conhece e também pelo que lhe é estranho, pelo imprevisto e surpresa, representados pelo Inconsciente. Visa que o indivíduo reconheça e assuma a sua participação diante da situação em que se encontra, por seu sofrimento, por sua vida (Forbes, 2012). E tal responsabilização é ainda mais importante no contexto atual, em que as formas de estabelecimento dos laços sociais encontram-se horizontalizadas.

Antigamente a referência para a constituição do sujeito era a relação familiar vertical, com a figura do pai como sendo a autoridade e o representante da lei e das proibições. Este tipo de constituição familiar e, portanto, de constituição do sujeito, não existe mais, pois as próprias relações familiares estão horizontalizadas. Hoje os pais não impõem proibições e não representam autoridade, mas são amigos de seus filhos. Isso representa uma perda dos referenciais tradicionais e daquilo que costumava dar sentido para a vida das pessoas. E justamente porque atualmente não existem regras e padrões a serem seguidos é cada vez mais importante que as pessoas se responsabilizem pelas consequências de seus atos. $\mathrm{O}$ homem busca cada vez mais sua realização pulsional, a satisfação de seus desejos, o que atualmente faz com menos impedimentos já que a lei se encontra enfraquecida (Forbes, 2012).

A perspectiva apresentada por Forbes (2012) a respeito da relação entre inconsciente, consciente e responsabilidade nos fornece subsídios para pensar sobre a intencionalidade do agressor no assédio moral. A partir da psicanalise o sujeito é responsável por todas as suas ações, independentemente de serem elas motivadas por conteúdos conscientes ou inconscientes. Ou seja, se a intenção do agressor/assediador era consciente ou inconsciente as consequências dessas serão as mesmas, bem como o nível de responsabilização que o sujeito deve ter em relação a essas, sem exceções.

Ao tratar especificamente sobre a intencionalidade no assédio moral Hirigoyen (2011) adota o mesmo posicionamento de Forbes (2012). De acordo com a psicanalista francesa, independentemente do nível de consciência que $o$ agressor tem de suas intenções destrutivas, as consequências e a responsabilidade dele por essas são as mesmas. O mesmo é válido para os colegas que foram omissos ao perceberem as agressões, permitindo a continuidade do processo violento e assim, do sofrimento solitário da vítima. (Hirigoyen, 2011).

Entende-se que a responsabilidade individual da qual tratam Forbes (2012) e Hirigoyen (2011) precisa ser contextualizada, caso contrário, cair-se-á no reducionismo psíquico como algumas abordagens do assédio que criticamos. De acordo com Horst e Soboll (2013) as práticas atuais de gestão estimulam a competitividade com o intuito de aumentar a produtividade por meio de um discurso sobre a importância de ser o melhor e estar constantemente buscando a excelência. Mas por trás desse discurso já naturalizado no ambiente institucional estimula-se a agressividade e a objetificação dos colegas de trabalho, que são vistos como entrave para o alcance da excelência e, por isso, devem ser passados para trás (Gaulejac, 2007). As hostilizações e humilhações repetitivas e duradouras que caracterizam o assédio moral podem surgir facilmente nesse tipo de contexto e serem estimuladas em prol da excelência.

Mas se por um lado há um estimulo ou permissividade por parte da organização 
em relação à prática do assédio moral, isso não quer dizer que as pessoas estão isentas de sua responsabilidade nesse processo. Trata-se de uma escolha individual corroborar com esse tipo de prática, isentar-se dela ou denunciá-la. Todavia, ainda que o nível de participação seja individual o combate ao assédio moral é coletivo e requer a transformação de modelo de gestão, conforme afirmam Horst e Soboll (2013).

Diante do exposto, considera-se que discutir se a intenção do agressor é inconsciente ou não e se havia premeditação ou conhecimento em relação ao que fazia, não implica em nenhum avanço para as discussões da intencionalidade, uma vez que a responsabilização das pessoas independe do nível de consciência da intenção. Abrir mão dessa discussão não significa, todavia, desresponsabilizar os atores sociais da prática do assédio moral, mas reforçar a responsabilidade e a participação que cada um possui em relação a essa problemática estimulada pelo próprio contexto. E neste sentido, cabe destacar a possibilidade de participação de cada um não só na prevenção do assédio moral, mas na busca de estabelecimentos de relações mais saudáveis.

Até aqui a intencionalidade como critério de caracterização do assédio moral foi questionada e problematizada. Mas ela é de grande importância para algumas áreas do conhecimento (Schatzmam et al., 2009), a exemplo da área da saúde, de gestão e do direito.

\section{A intencionalidade no assédio moral e implicações práticas na clínica, na gestão e no direito}

A intencionalidade é relevante para a avaliação no contexto da clínica médica e psicológica. A percepção de que alguém quer the prejudicar tem um impacto psicológico maior do que, por exemplo, acreditar que isso aconteceu em virtude de uma conjuntura qualquer ou como um efeito colateral de outra ação (Schatzmam et al., 2009). Ou seja, a percepção da vítima de que a violência que sofre ou sofreu foi intencional é um componente fundamental para ocorrência ou agravamento do dano psíquico (Soboll, 2013).

De acordo com Evangelista e Menezes (2000) o dano psíquico refere-se ao prejuízo e efeito negativo decorrente de algum evento traumático cuja gravidade é variável. Ele pode ser entendido como fruto de uma situação tão negativa que a pessoa não consegue enfrentar e se adaptar as mudanças por ele ocasionadas, e habitualmente é causado por fatos ameaçadores à vida e integridade psicológica, por lesões físicas graves, pela percepção da vítima de que o dano foi causado intencionalmente, por uma perda violenta ou exposição ao sofrimento de outros (Rovinski, 2005).

Mediante o dano psíquico leve o indivíduo apresenta comportamentos reativos que alteram a dinâmica da personalidade e a vida cotidiana, acarretando mudanças na vida social, profissional, afetiva e sexual que requerem apenas tratamento focal e breve. Um dano psíquico grave resulta em adoecimento e tem consequências muito mais severas para o indivíduo, podendo levá-lo a desenvolver episódio depressivo com sintomas psicóticos, alterações psicomotoras, ideias alucinatórias ou delirantes. Há o comprometimento de todas as esferas da vida do sujeito, havendo o risco de morte por suicídio, desnutrição ou desidratação (Evangelista \& Menezes, 2000).

A verificação da existência do dano é importante e, quando provada a partir da avaliação psicológica, deve ser seguida da caracterização dos efeitos que o evento danoso teve para a vítima, que deve ser seguido pela revalorização de seu papel social (Rovinski, 2005).

Schatzmam et al. (2009) afirmam que, além da área da saúde, esclarecimentos sobre o critério da intencionalidade no assédio são 
importantes para a realização de intervenções da área de gestão de pessoas em empresas. Ainda que a intencionalidade seja clara, as intervenções devem também alcançar o nível organizacional, porque a prática desse tipo de violência não ocorre se a organização não oferecer um terreno fértil, seja por negligencia, incentivo ou conivência. Portanto, a intervenção deve ser sempre direcionada também para a organização do trabalho e para as políticas empresariais.

Além destas áreas do conhecimento, no direito muito tem se estudado sobre intencionalidade no assédio moral (Alkimin, 2013). As especialidades do Direito que se ocupam dessa problemática são o Direito cível ou do trabalho, dependendo de se tratar de uma relação de trabalho (genérica) ou emprego (específica) (Pinto, s/d). No Direito o assédio moral é uma forma de violação das obrigações contratuais e dos direitos de personalidade do trabalhador, visto que atinge suas características pessoais e profissionais. Ou seja, traz prejuízos para a vida pessoal (auto-estima, por exemplo) e laboral, afetando a produtividade e podendo resultar até mesmo em suicídio (Alkimin, 2013).

$\mathrm{O}$ assédio moral viola alguns dos valores humanos fundamentais: dignidade, honra, igualdade e pessoalidade, os quais são protegidos pela Constituição Federal e considerados direitos fundamentais da pessoa humana. $\mathrm{O}$ desrespeito desses direitos resulta em danos que podem ser de ordem material ou patrimonial e/ou imaterial, os quais compreendem danos psicológicos, morais e físicos. No caso do assédio moral os danos morais $\mathrm{e}$ psicológicos são mais comuns (Pinto, s/d).

A vítima do assédio tem violados seus direitos de personalidade, o que resulta em dano moral e fere a dignidade da pessoa humana. A lei da constituição federal protege a dignidade de pessoa humana e garante a tutela jurídica contra o dano moral, sem prejuízos patrimoniais. Assim, é do empregado a responsabilidade pela violação contratual e abuso de poder (Alkimin, 2013).

$\mathrm{O}$ assédio moral "implica grave violação do dever contratual e de outras hipóteses legais previstas no art. 483 da CLT; portanto, o empregado, vítima do assédio moral, pode lançar mão da rescisão indireta, além de invocar a estabilidade no emprego no caso de demissão arbitrária, uma vez manifestando problemas de saúde como sequelas do assédio moral" (Alkimin, 2013, p. 03).

Apesar da popularidade da problemática, ainda não existe no Brasil uma legislação federal para tratar do assunto, apenas projetos de lei no âmbito penal, além de leis municipais e estaduais que disciplinam e conceituam o assédio no âmbito da administração pública (Alkimin, 2013). Por esse motivo o assédio moral vem sendo abordado a partir de jurisprudências. Segundo o site do $\mathrm{STF}^{4}$, essas são orientações que resultam de um conjunto de decisões judiciais proferidas num mesmo sentido sobre determinada matéria. Assim, os operadores do Direito podem, ao tratar do assédio moral, se utilizar das leis de outros países como subsidio teórica, teorias jurídicas e decisões anteriores dos tribunais a esse respeito (Thomé, 2013).

Alguns itens são intrínsecos no tratamento da jurisprudência, ou seja, devem ser considerados para que a violência seja configurada como assédio moral. São esses: a) o dano, entendido como degradação das condições de trabalho, b) ataque às condições psíquicas e físicas do empregado e c) repetição, ou seja, o dano ou ofensa devem ser recorrentes e prolongados (Thomé, 2013).

A intencionalidade é considerada como elemento extrínseco à jusrisprudência, ou seja, são considerados necessário ou desnecessário conforme o entendimento da doutrina ou jurisprudência (Thomé, 2013) e pode

4

http://www.stj.jus.br/portal stj/publicacao/engine.w sp?tmp.area $=333$ 
modificar o valor da indenização a ser paga (Schatzmam et al, 2009). A maioria dos países que possuem uma legislação sobre o assédio entende que esse é um elemento extrínseco, ou seja, que o assediador pode atuar sem se dar conta do que faz (Thomé, 2013).

Pinto (s/d), docente da Academia Nacional de Direito do Trabalho, diferentemente, afirma que a existência do assédio moral é avaliada pelos juristas apenas a partir dos seguintes elementos: a) conteúdo psicológico: avaliar se está presente a intenção de destruir a personalidade; b) repetitividade: recorrência das agressões ao longo do tempo; c) dano psíquico ${ }^{5}$ : é a comprovação pericial de que as agressões resultarem em adoecimento da vítima, critério contraditório entre os juristas (pinto, s/d).

"Dada a variedade de hipóteses e pelas dificuldades que oferece à positivação de sua prática, a caracterização do assédio moral civil ou trabalhista ganha notável relevo no conjunto deste estudo. Por um primeiro ângulo, suas formas se diversificam tanto que inviabilizam toda tentativa de enumeração taxativa; ela terá que ser, necessariamente, exemplificativa (ver n. 6 supra), cabendo ao intérprete ou julgador definir $o$ reconhecimento caso a caso, partindo do exame dos elementos constitutivos [enumerados acima], aqui alinhados numa espécie de hierarquia calcada na ênfase dos traços com que contribuem para completar o perfil [da situação]" (Pinto, d/s, p. 8)

Portanto, as pesquisas realizadas demonstram que há divergências quando a consideração da intencionalidade para a caracterização do assédio moral. Essa

5 O dano psíquico é prejuízo na esfera psíquica, enquanto o dano moral refere-se ao prejuízo ou atentado a dignidade, honra, igualdade. divergência foi reafirmada a partir do breve levantamento bibliográfico realizado no site Jusbrasil ${ }^{6}$, o qual apontou que a intencionalidade tem sido considerada com frequência pelos operadores do Direito e negligenciada por outros, de modo a deixar bastante margem para o entendimento individual de cada um sobre a questão. Foram selecionados, em virtude do conteúdo, três casos em que a intencionalidade foi considerada pelos juristas no julgamento dos casos de assédio.

\section{$\rightarrow$ Caso 1: TRT 24, Processo $\mathbf{N}^{\circ}$ 0257/2008-071-24-00-3-RO-Mato Grosso do Sul.}

Teor: pedido de indenização por danos morais em que o reclamante, do sexo masculino, exercia cargo equivalente ao do gerente, ocupando o segundo cargo mais alto da hierarquia. Alega que, depois de ser transferido para uma filial da empresa situada em outra cidade, teve sua chefia desautorizada pela instituição, seus projetos deixaram de receber apoio e formou-se um complô contra ele; era rotulado de incompetente pelos superiores e subordinados, fatos que culminaram em sua demissão. Foram chamadas como testemunhas a supervisora do reclamante e alguns de seus colegas de trabalho, os quais descaracterizam as suas alegações.

O desembargador da turma, ao analisar o caso, considerar a falta de comprovação da intencionalidade para descaracterizar a conduta como assédio moral:

"Creio que, na maioria das vezes, o que houve foi falta de apoio aos projetos e iniciativas do empregado. Por mais desagradável que seja não caracteriza tal atitude como assédio moral organizacional, até porque a prova não demonstrou que a reclamada procedesse com tal

${ }^{6}$ www.jusbrasil.com.br 
intuito, o que basta para que se rejeite a tese encampada pelo obreiro" (Grifos nossos).

A intencionalidade também aparece em outros trechos dos autos:

"A distinção entre o assédio moral e o abuso do poder diretivo empresarial reside também no fato de que, enquanto no assédio, em regra, se visa atingir a alma da vítima, no abuso do poder empresarial o que se pretende é tornar o trabalhador mais produtivo, de maneira que o maltrato psicológico e as condutas humilhantes e vexatórias constituem um meio para alcançar dita finalidade. Com efeito, reitero a convicção de que não houve prova da ‘perseguição” (Grifos nossos)

No caso acima se percebe que a não constatação da intenção de causa algum prejuízo ao requerente por parte de empresa, realizada por meio de depoimentos, foi suficiente para descaracterizar o assédio moral. Fica assim evidente a importância desse critério para o magistrado.

\section{$\rightarrow$ Caso 2: Recurso Ordinário $\mathbf{N}^{\circ}$ 01281-2006-462-05-00-3-RO - Bahia}

Teor: Pedido de indenização por dano moral e material realizado pelo funcionário de um banco em virtude do abuso do poder diretivo do empregador. $\mathrm{O}$ requerente alega que a gestão do banco impunha metas impossíveis de serem atingidas e amaçava demitir aqueles que não as atingissem, motivo pelo qual o ambiente de trabalho era bastante estressante e a tensão generalizada. A isso acrescenta a tratamento diferenciado que passou a ter de sua inspetora, a qual era demasiadamente rude e agressiva. Esse cenário levou-a a fazer uso de medicamentos calmantes fortíssimos.
Segue a análise do juiz, reproduzida parcialmente aqui:

“(...) a configuração do assédio moral pressupõe, portanto, três elementos básicos: ação ou omissão abusiva, perversa e implacável (intencionalidade da conduta); ostensiva e reiterada (permanência no tempo); com objetivo de desestabilizar emocionalmente o obreiro, causando-lhe um dano psíquico ou moral, para marginalizá-lo no ambiente de trabalho, ou a fim de que peça ele demissão e se afaste da empresa."

"O assédio moral resulta em danos materiais ou extrapatrimoniais (dano moral), sendo que este independe de prova, vale dizer, é presumível. $O$ que se coíbe é a conduta lesiva do agente assediador, ou seja, o assédio moral como violação de um direito à dignidade da vítima. Desse modo, uma vez provada conduta ilícita do empregador que caracterize assédio moral, dá-se ensejo à responsabilidade civil subjetiva deste, porquanto provados os três elementos essenciais para a sua configuração - o dano, o nexo causal entre este e a conduta abusiva do empregador, e o elemento anímico (o dolo)."

A partir dos elementos acima e das provas testemunhais coletadas, o jurista conclui:

"Com efeito, num contexto empresarial capitalista, a busca por aumento de produtividade e, em última instância, de lucros é desiderato de todo os empresários, embora não possa ser alcançada mediante ofensa à integridade emocional de seus empregados. Desse modo, a fixação de metas, bem assim a cobrança de seu cumprimento, são procedimentos 
absolutamente aceitáveis, porquanto se inserem na órbita do poder diretivo do empregador a que alude $o^{\prime \prime}$ caput "do art. $\underline{2}^{\circ}$, da $\underline{\text { CLT }}$ "

Nesse caso ainda que a intencionalidade não tenha sido premente na descaracterização do assédio pela empresa, ela foi um critério considerado na análise. Mas sua relevância existe apenas conjuntamente para esse magistrado, cujo julgamento baseia-se no atendimento de todos os elementos elencados, ao contrário do que se observa no caso anterior.

\section{$\rightarrow$ Caso 3 - TRT-5 - Recurso Orsinário $\quad N^{\circ} \quad 0128100$ - 72.2006.5.05.0462 - Bahia}

Teor: reclamante, funcionária de órgão de assistência de banco público brasileiro alega ter sofrido assédio moral após ser promovida para coordenadora e gerente de compras e contratação. Afirma que além da sobrecarga de trabalho não recebia respaldo institucional para desenvolver as suas atividades. Foi dispensada de sua função de modo injustificado um mês depois de retomar seu trabalho, da qual havia sido afastada por doença pelo INSS durante três meses.

O posicionamento do juiz está reproduzido abaixo:

"No caso dos autos, a Autora afirmou que as pressões por produtividade eram exercidas sobre todos os empregados e que a pecha de incompetência era dirigida à sua área de trabalho. Ou seja, não se observa no caso em questão perseguição pessoal à Reclamante. A dois aspectos profundamente relevantes na caracterização do assédio moral, a intencionalidade do agente e a pessoalidade da vítima. Isto é, o agente agressor visa atingir pessoalmente a vítima."
Como a reclamante foi afastada devido ao "excesso de estresse" o magistrado diferencia o assédio moral da gestão por estresse, destacando a intencionalidade como um elemento importante para caracterização do primeiro.

"o objetivo consciente da gestão por estresse não é destruir os empregados, mas, ao contrário, melhorar seu desempenho. $O$ propósito é o aumento da eficiência ou da rapidez na realização de uma tarefa. Se a gestão pelo estresse provoca consequências desastrosas sobre a saúde, é por uma alteração imprevista, uma dosagem errada (mesmo que, nos seminários de gestão do estresse, tente-se ensinar os executivos a suportar melhor a pressão!). Mas no estresse, contrariamente ao assédio moral, não existe intencionalidade maldosa. Já no assédio moral, o alvo é o próprio indivíduo, com um interesse mais ou menos consciente de prejudicá- lo. Não se trata de melhorar a produtividade ou otimizar os resultados, mas se livrar de uma pessoa porque, de uma maneira ou de outra, ela incomoda'. Tal violência não é útil à organização nem à boa administração da empresa. "[Grifos nossos].

"Para ensejar o deferimento de indenização por danos morais, mister se faz verificar se o dano sofrido (adoecimento) remanesceu de conduta dolosa ou culposa da Ré (responsabilidade subjetiva) e se há o necessário nexo causal (...)Assim, entendo que a Reclamada agiu dentro dos limites de seu poder diretivo, não restando demonstrado qualquer intuito de perseguição ou humilhação à Reclamante. Nego provimento ao recurso" [Grifos nossos]. 
A partir dos argumentos acima, os desembargadores do Tribunal Reginal do Trabalho deferem o pedido de assédio moral por parte da reclamante.

Os casos relatados demonstram que a intencionalidade tem sido considerada um critério para a caracterização ou descaracterização do assédio moral por muitos operadores do Direito, o que reafirma a proposição de Pinto (s/d) de que a especificidades de cada caso e a ausência de uma legislação especifica sobre o assédio moral deixa a cargo do magistrado quais ou como considerar os critérios definidores do assédio moral.

\section{CONSIDERAÇÕES FINAIS}

O presente artigo teve como objetivo a problematização da intencionalidade enquanto critério para a caracterização do assédio moral no contexto do trabalho. A partir dele foi possível constatar que a intencionalidade é abordada com frequência, entretanto com superficialidade na literatura sobre 0 assédio moral. As discussões sobre a intencionalidade, centradas na sua importância para a caracterização ou definição do assédio moral no trabalho, são permeadas por incongruências, indefinições e contradições.

A intencionalidade não é definida pelos autores apesar da importância dada na caracterização do assédio moral. Ela está associada ao agressor, ou seja, de acordo com a grande parte da literatura sobre assédio moral, tratar de intencionalidade é abordar a intenção ou objetivo que o agressor possui com as agressões e humilhações. Há uma tendência equivocada em tratar a intenção do agressor como equivalente ao objetivo do assédio moral.

Os autores que defendem a intencionalidade como critério obrigatório abordam o assédio moral com destaque a elementos pessoais e relacionais, considerando apenas a perspectiva daquele que vivenciou as agressões (vítima) sem entrar no mérito de como mensurá-la. Por outro lado, os autores que prescindem dela na caracterização consideram justamente a dificuldade e a impossibilidade de comprovar a sua existência ou mensurar sua intensidade. Estes autores reconhecem também que $\mathrm{o}$ assédio pode ser tanto consciente quanto inconsciente, ainda que o nível de consciência não altere em nada a responsabilidade dos envolvidos diante dos resultados de suas ações.

Os elementos acima levaram a percepção de que a discussão sobre a intencionalidade tem suas raízes na forma como o assédio moral tem sido predominantemente abordado: psicologizada, moralizada e considerando apenas $\mathrm{o}$ relato de vítimas. A análise da violência psicológica a partir dessa perspectiva unilateral coloca que a causa da violência é a intencionalidade, vontade que o agressor tem de destruir a vítima. A intenção é, por sua vez, relacionada com componentes morais, no caso com a maldade. O resultado é a compreensão da violência como fruto da intenção maléfica e destrutiva de uma única pessoa, o agressor.

Conforme pôde ser observado em três ações julgadas pelo Judiciário Brasileiro, o resultado da utilização desse viés de análise do assédio moral, tende a desconsiderar o contexto socioeconômico e organizacional, produzindo culpados solitários. Nesta perspectiva o agressor é o único culpado pelas humilhações e agressões que dirige para a frágil vítima no intuito de destruí-la. A culpabilização do agressor resulta na manutenção das verdadeiras causas da violência, ocultadas pela perspectiva de abordagem do assédio restrita a vítima e ao agressor. Logo, deixa a margem o contexto socioeconômico que favorece e até motiva as práticas de assédio moral com vistas ao aumento da produtividade e lucro. A quem interessa que o assédio moral continue sendo tratado como um problema relacional entre vítimas e agressores que "escolhem" o trabalho 
como palco de seus embates? As análises sobre a intencionalidade no assédio moral podem evidenciar algumas das lacunas no tratamento prático dos casos e por isso foram objeto deste ensaio.

\section{Referências}

Alkimin, M. A. (2013). Assédio moral na relação de trabalho. Curitiba: Juruá.

Barreto, M. (2013). Assédio moral: trabalho, doenças e morte. In: Seminário compreendendo o assédio moral no ambiente de trabalho, Florianópolis. Anais. São Paulo: Fundacentro, 2013, p. 13-26. Retrieved from: http://www.assedio moral.ufsc.br/file s/2013/03/Seminario-CombateAMT-Fundacentro-2013.pdf. Acesso em 25 de outubro de 2013.

Chappell, D. \& Di Martino, V. (2006). Violence at work. Third edition. Geneva: International Labour Office.

Dejours, C. (2007). Psicodinâmica do trabalho na pós-modernidade. In: Mendes, A. M., Lima, S.C.C., \& Facas, E. P. (Org). Diálogos em Psicodinâmica do trabalho. Brasîlia: Paralelo.

Di Martino, V., Hoel, H. \& Cooper, C. L. (2003). Preventing violence and hassment in the workplace. European Foundation for the Improvement of Living and Working Conditions. [Eurofound]. Ireland.

Di Martino, V. (2011). Workplace violence in the health sector: relationship between work stress and workplace violence in the health sector. International Labour Office, Internacional Council of Nurses, World Heath Organization, Public
Services International. Geneva: International Labour Office.

Einarsen, S. (2000). Harassment and bullying at work: A review of the Scandinavian approach. Aggression and Violent Behavior, 4(5), p. 379401.

Einarsen, S., Hoel, H., Zapf, D., \& Cooper, C. L. (2003) The concept of bullying at work. In: Einarsen, S, Hoel, H., Zapf, D. \& Cooper, C. L. (Eds.), Bullying and emotional abuse in the workplace (v. 1, pp. 3-30). EUA: CFC Press.

Einarsen, S., Hoel, H., Zapf, D. \& Cooper, C. L. (2010). Bullying and harassment at work: developments in theory, reseach and practice.

Segunda edição. EUA: CFC Press.

Evangelista, R. \& Menezes, I. V. (2000). Avaliação do dano psicológico em perícias acidentárias. Revista IMESC, 2, 45-50. Retrieved from: http://www.imesc.sp.gov.br/pdf/art2r ev2.pdf.

Freitas, M. E. (2007). Quem paga a conta do assédio moral no trabalho?. RAEeletrônica. Brasil: Escola de Administração de Empresas de São Paulo. Retrieved from: http://www.redalyc.org/pdf/2051/205 114655011.pdf

Freitas, M. E., Heloani, R. \& Barreto, O. M. (2008). Assédio Moral no Trabalho. São Paulo: Cengage Learning.

Ferreira, J. B. (2009). Perdi um jeito de sorrir que eu tinha: violência, assédio moral e servidão voluntária no trabalho. Rio de Janeiro: 7Letras. 
Forbes, J. B. (2012). Inconsciente e responsabilidade: Psicanálise do século XXI. Baueri, SP: Manole.

Gaulejac, V. (2007). Gestão como doença social: ideologia, poder gerencialista e fragmentação social. Aparecida, SP: Idéias e Letras.

Glina, D. M. R. (2010). Assédio moral no trabalho. In: Glina, D. M. R., Rocha, L. E. Saúde mental: da teoria à prática. (p. 427-436). São Paulo: Roca

Glina, D. M. R. \& Soboll, L. A. (2012). Intervenções em assédio moral no trabalho: uma revisão da literatura. Rev. bras. saúde ocup. Retrieved from: http://www.scielo.br/scielo.php?scrip $\mathrm{t}=$ sci_arttext\&pid=S0303$76572012000200008 \& \operatorname{lng}=$ en $\& \mathrm{nrm}=$ iso

Heloani, R. \& Barreto, M. (2010). Aspectos do trabalho relacionados à saúde mental: assédio moral e violência psicológica. In: Glina, D. M. R. \& Rocha, L. E (Eds). Saúde mental: da teoria à prática. (p. 3148). São Paulo: Roca.

Heloani, R. \& Barreto, M. (2013). Assédio moral e sexual. In: Vieira, F. E., Mendes, A. M \& Merlo, A. R. C. (Orgs). Dicionário Crítico de Gestão e Psicodinâmica do trabalho. (p. 5559). Curitiba: Juruá.

Hirigoyen, M. F. (2009). Assédio Moral: a violência perversa no cotidiano. $5^{a}$ edição. Rio de Janeiro: Bertrand Brasil.

Hirigoyen, M. F. (2011). Mal-estar no trabalho: redefinindo o assédio moral. Rio de Janeiro: Bertrand.
International Labour Office, International Council of Nurses, World Health Organization, Public Services International (2011). Framework guidelines of addressing workplace violence in the health sector. Geneva: International Labour Office.

Pinto, J. A. R. (2013) Contribuição do direito do trabalho para o combate ao assédio moral nas relações humanas. Revista LTr Legislação do Trabalho, v. 77, n. 7, p. 787-794

Rovinski, S. L. R. (2005). A avalição do dano psíquico em mulheres vítima de violência. In: Shine, S. (org). Avaliação psicológica e lei: adoção, vitimização, separação conjugal, dano psíquico e outros temas. (p. 175-179). São Paulo: Casa do Psicólogo

Schatzmam, M. (2009). A violência moral sob a luz de categorias de Bordieu, Veroné do circulo de Bakhtin. In: Soboll, L. A., Gosdal, T. C. (org). Assédio moral interpessoal e organizacional: um enfoque interdisciplinar. (p. 94-105). São Paulo: LTr

Schatzmam, M., Gosdal, T. C., Soboll, L. A. \& Eberl, A. D. (2009) Aspectos definidores do assédio moral. In: Soboll, L. A., Gosdal, T. C. (org). Assédio moral interpessoal e organizacional: um enfoque interdisciplinar, São Paulo: LTr.

Soboll, L. A. (2011). Assédio Moral no Trabalho. In: Cattani A. D. \& Holzmann, L. (org). Dicionário de trabalho e tecnologia. p. 40-48. Porto Alegre, RS: Zouk

Soboll, L. A. \& Heloani, J. R. (2008). A origem das discussões sobre assédio moral no Brasil e os limites conceituais. In: Soboll, L. A. (org). 
Assédio moral/organizacional: uma análise da organização do trabalho. p.17-33. São Paulo: Casa do Psicólogo.

Soboll, L. (2017). Intervenções em assédio moral. São Paulo: Ltr.

Vieira, C. E. C., Lima F. P. A. \& Lima, M. E. A. (2012). E se o assédio não fosse moral? Perspectivas de análise de conflitos interpessoais em situações de trabalho. Rev. bras. saúde ocup., v. 37, n. 126

Data de submissão: 06/07/2017

Data de aceite: 14/09/2017 